\title{
Cultivo in vitro de Scoparia dulcis $L$. (Scrophulariaceae)
}

\author{
Marco Cernal,*, Valdano Tafur ${ }^{2}$ \\ I Centro de Investigación y Valoración de la Biodiversidad (CIVABI), Universidad Politécnica Salesiana, Quito, Ecuador. \\ 2 Laboratorio de Biotecnología, Universidad Central del Ecuador, Quito, Ecuador. \\ * Autor para correspondencia: mcerna@ups.edu.ec.
}

\section{Resumen}

En la presente investigación se diseñaron las técnicas para la propagación de tejido meristemático presente en las yemas de la especie Scoparia dulcis L, (Scrophulariaceae), obteniendose plántulas genéticamente idénticas a la planta madre. Esta práctica permite reducir el espacio y el tiempo necesario para el cultivo de la planta. Con el protocolo desarrollado se podrá obtener especímenes de alto rendimiento en principios activos y libres de agentes infecciosos, especialmente en la producción de material requerido en la elaboración de productos medicinales. La especie en estudio ha sido referida con propiedades antimaláricas, entre sus componente químicos esta el beta sitosterol utilizado como desinflamante de la próstata y elemento básico para tratamientos de la calvicie. Para desarrollar el cultivo in vitro se definió primero el método para desinfección de explantes de bacterias y hongos; para lo cual se ensayaron los tiempos de exposición de los explantes en hipoclorito de sodio al 2,25\% y $3 \%$. Además, se determinó el medio de cultivo in vitro ideal, partiendo del medio básico de Murashige y Skoog, al cual se añadieron las hormonas de crecimiento IBA, ANA y 2,4-D. Se incluye el ensayo de adaptación de la especie a un medio rústico en condiciones ambientales poco controladas. La desinfección de los explantes se realizó a 23 minutos en hipoclorito de sodio al $3 \%$ y el cultivo in vitro necesitó un medio básico de Murashige y Skoog, sin hormonas de crecimiento.

Palabras clave: Cultivo in vitro, totiopotencialidad, medios de cultivo, segmento nodal, hormonas, Scoparia dulcis.

\begin{abstract}
In the framework of this investigation the techniques were designed for the propagation of meristematic tissue present in the bud of the nodal segments of the species, Scoparia dulcis L. (Scrophulariaceae), thereby obtaining plants genetically identical to the mother plant. They were identical to the plant mother. These techniques help to reduce the space and time necessary for the cultivation this species. The protocol thus developed will produce specimens of high performance in active principles and free of infectious agents, particularly for the production of material required for medicinal products. Scoparia dulcis L. has been described with anti-malarial proprieties. One of its chemical components is beta sitosterol, which is used to cure prostate inflammation and constitutes a base element for the treatment of baldness. The research was developed in several stages: first, the establishment of a protocol for bacterial and mushroom disinfection of explants. With this purpose the times of explants exposition to sodium hypochlorite $2,25 \%$ and $3 \%$ were tested. The second stage was to determine the ideal in vitro cultivation environment. The basic environment was Murashige and Skoog, to which several growth hormones (IBA,ANA y 2,4-D) were added.The last stage was to test the adaptation of the species to a rustic low-level control environment. Explant disinfection was conducted in sodium hypochlorite 3\% for 23 minutes. in vitro cultivation required a basic environment of Murashige and Skoog without growth hormones.
\end{abstract}

Key words: in vitro cultivate; totioponteciality, cultivation means, nodal segment, hormones, Scoparia dulcis.

La Granja 9(I): 44-5I. 2009.

(C) 2009, Universidad Politécnica Salesiana, Ecuador. 


\section{Introducción}

El cultivo de tejidos vegetales o cultivo in vitro de tejidos vegetales, es una técnica de reproducción en condiciones totalmente asépticas, en la que a partir de un pequeño segmento inicial de tejido es posible regenerar en poco tiempo miles o millones de plantas genéticamente iguales a la planta madre, esto se logra mediante la aplicación a un tejido vegetal de estímulos físicos y químicos controlados en un medio de cultivo.

A diferencia de las técnicas tradicionales de cultivo, esta técnica biológica permite la propagación de grandes volúmenes de plantas en menor tiempo; así como el manejo de las mismas en espacios reducidos, Roca y Mroginski (199I). Por otro lado, la técnica es de gran utilidad en la obtención de plantas libres de patógenos, la producción de plantas en peligro de extinción, estudios de ingeniería genética, etcétera. El enorme potencial de la técnica ha favorecido en los últimos años el incremento del número de laboratorios de cultivo de tejidos para la producción comercial de plantas ornamentales, medicinales y frutales (Pierik, 1987).

Con esta perspectiva se propuso investigar las técnicas de cultivo in vitro de la especie Scoparia dulcis L (Scrophulariaceae) (Figura I), para utilizarla en el procesamiento de productos medicinales; para esto fue necesario determinar los métodos de desinfección de los segmentos nodales para su propagación, e identificar los nutrientes requeridos para elaborar un medio de cultivo ideal para propagar la especie en estudio.

\section{I Distribución}

De acuerdo con datos de colecciones registrados en la base de datos "TRÓPICOS" (2002) la especie Scoparia dulcis $L$, es una planta herbácea nativa, de la cual se registran colecciones en Galápagos, los Andes y la Amazonía, su nivel altitudinal está entre 0 y 2.500 msnm.

\subsection{Propiedades y acciones reportadas de Scoparia dul-} cis $L$

Controla virus, impide el crecimiento de células de leucemia, inhibe los tumores, controla microbios, reduce inflamación, alivia el dolor, reduce los espasmos, expulsa flema, promueve la menstruación, reduce la tensión, regula el ritmo cardíaco. Tiene propiedades antibacteriales, reduce la fiebre, cura heridas, disminuye el nivel de azúcar en la sangre y regula la temperatura corporal (Taylor, 2005). Se cree además que tiene propiedades anti maláricas. TRÓPICOS (2002).

\subsection{Análisis químico de Scoparia dulcis $L$.}

Para esta especie se reportan los siguientes compuestos químicos:

Acacetina, Amirina, Apigenina, Benzoxazina, Benzoxazolina, Benzoxazolinona, Ácido betulínico, Cirsimarina, Cirsitakaosida, Coixol, Ácido cumarínico, Cynarosida, Daucosterol, Dulcinol, Ácido dulcioico, Friedelina, Ácido gentísico, Glutinol, Himenoxina, Ácido ifflaionico, Linarina, Luteolina, Mannitol, Scopadiol, Ácido scopadulcico A y B, Scopadulciol, Scopadulina, Ácido scoparico A y C, Scparinol, Scutellareina, Scuterrarina, Sitosterol, Stigmasterol, Taraxerol, Vicenina, Vitexina. (Taylor, 2005).

\subsection{Nombres comunes de Scoparia dulcis $L$}

Brush; bitter Brush (Paraguay), Escobilla (Colombia; Perú), Tiatina, Teatina (Ecuador), Vassourinha (Brasil), Pichana de ñuñco (Perú), Broomweed, Hierba de regaliz (EE.UU.). Otros nombres: anisillo, bitterbroom, borohemia, sirpi de brum, mastuerzo, pichana de piqui, pottipooli, escoba dulce, tapixava, tupixaba. (Taylor, 2005).

\section{Materiales y métodos: Establecimiento de los cultivos in vitro}

\section{I Predesinfección}

Los explantes iniciales se obtuvieron de segmentos nodales, de plantas jóvenes sin floración y se lavarán con agua corriente y detergente.

\subsection{Desinfección}

Dentro de una campana de flujo laminar los segmentos nodales de Scoparia dulcis L, se sumergieron en una solución de hipoclorito de sodio $(2,25 \%$ y $3 \%$ ) en constante agitación durante varios tiempos $(15,20$, $25,30,35$ y 40 minutos), se aplicaron tres enjuagues con agua destilada estéril de tres minutos cada uno.

\subsection{Siembra}

Con la ayuda de un bisturí se cortaron sobre servilletas estériles, segmentos de $+/-0,5 \mathrm{~cm}$ de largo, que tenían un nudo y se sembraron en frascos estériles de $250 \mathrm{ml}$ que contenían $20 \mathrm{ml}$ del medio de cultivo (Figura 2). Luego fueron sellados con papel aluminio y plástico de embalaje (rollo pack).

La siembra de tejidos se realizó en un medio nutritivo de acuerdo a la formulación de Murashige \& Skoog (1962) y Pierik (1987); complementado con variaciones de hormonas: IBA, ANA y 2,4-D.

El pH del medio de cultivo se ajustó a 5,8. La esterilización de los medios de cultivo se lo ajustó a 20 libras de presión durante 20 minutos. 


\section{Scoparia du/cis Linnaeus}

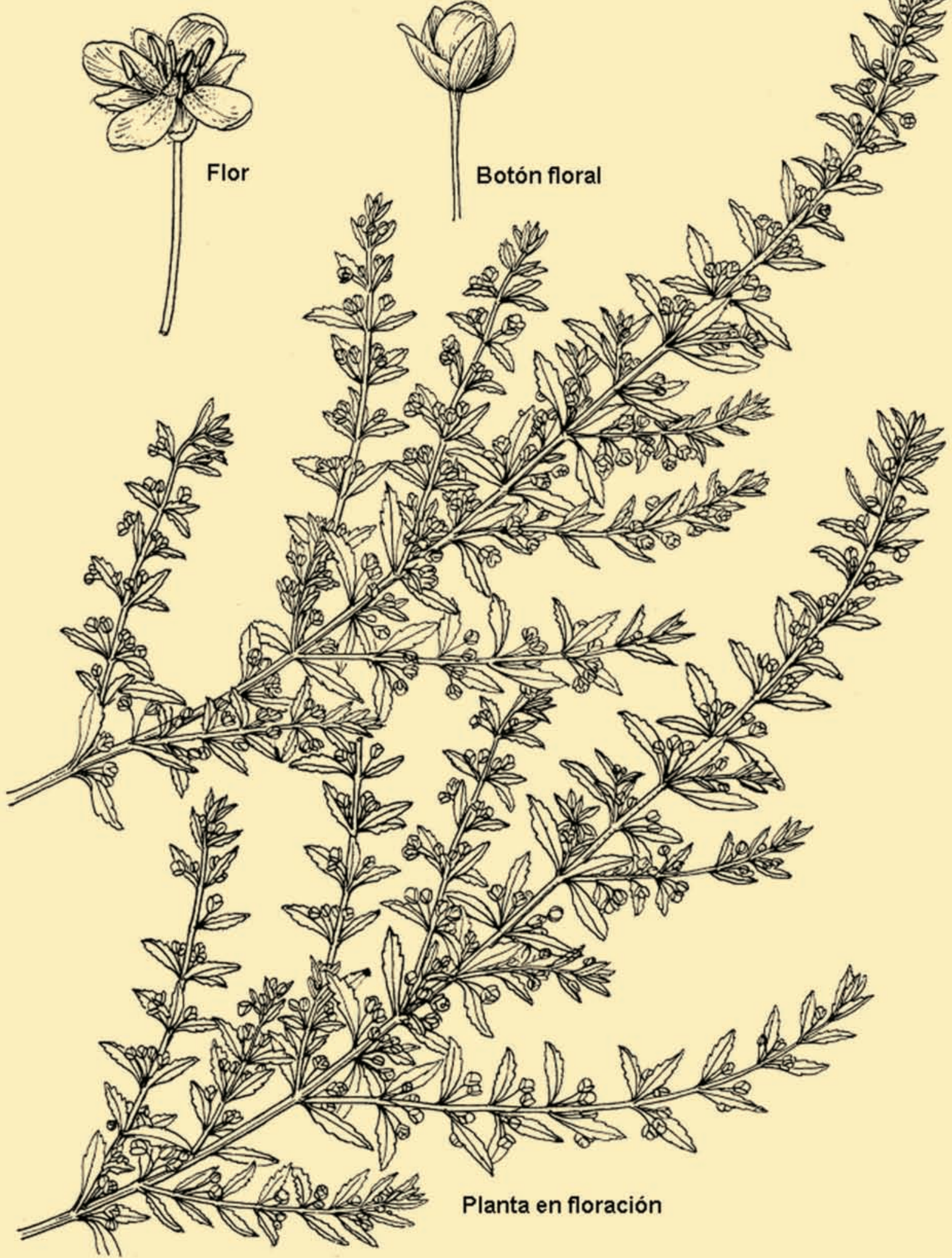

Figura I. Escoparia dulcis L,. En floración, es una hierba de 8 a $25 \mathrm{~cm}$, tiene hojas opuestas dentadas, con muchas flores blancas pequeñas, frutos maduros verde - cafés. Jiemei, Xu y ji Chaozhen (1976). 


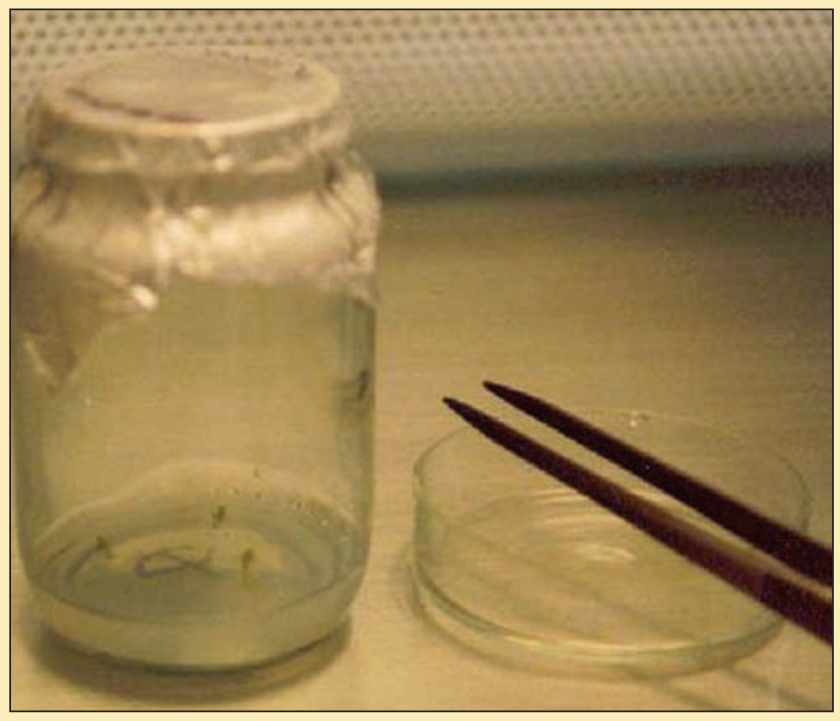

Figura 2. Siembra de segmentos de Scoparia dulcis $L$ en medios de cultivo. Fuente: Marco Cerna.

Bajo estas condiciones, los frascos con los explantes se trasladaron a una cámara de incubación la cual se mantiene a una temperatura de $25 \pm 2{ }^{\circ} \mathrm{C}$, y bajo una intensidad luminosa de 2.000 lux (lámparas fluorescentes), tal como se muestra en la (Figura 3).

\section{Resultados:}

4.I Desinfección de nódulos

Los resultados se muestran a continuación (Tabla I).

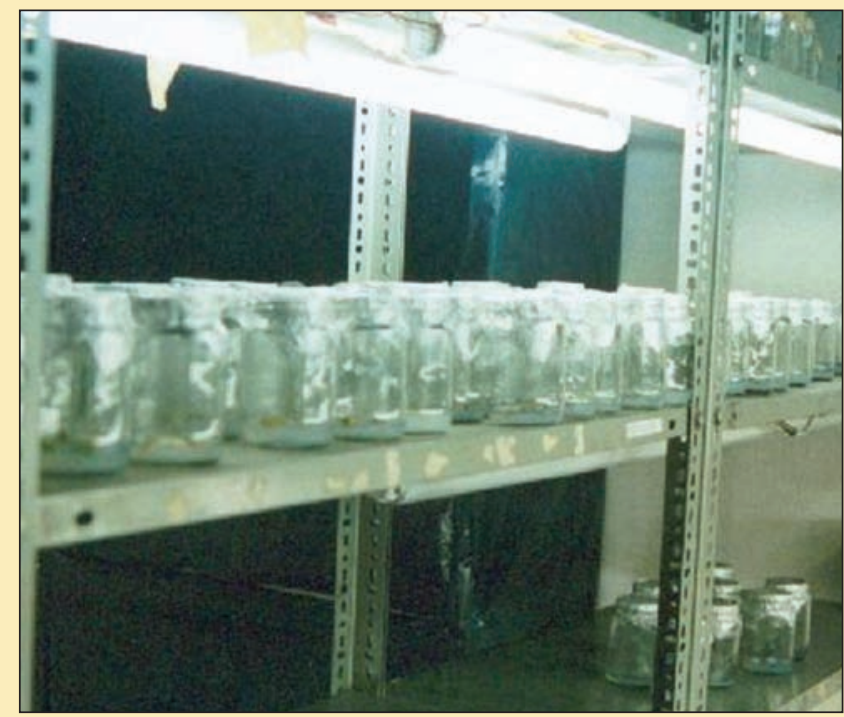

Figura 3. Cámara de cultivo. Fuente: Marco Cerna.

Una etapa crucial en el desarrollo de cultivos in vitro es la desinfección del material vegetal, para lo cual en esta investigación se determinó el tiempo que deben estar sumergidos los segmentos nodales de Scoparia dulcis $L$, en solución de hipoclorito de sodio, así se encontró que el tiempo ideal es de 20 a 25 minutos, en una solución concentrada al $2,25 \%$; pudiendo ser también 10 minutos en una solución al 3\% de hipoclorito de sodio; este procedimiento se debe realizar en el interior de la cámara de flujo laminar. 4.2 Medios de cultivo:

Tabla I. Resultados de la desinfección de segmentos nodales, en Cultivo in vitro de Scoparia dulcis L (SCROPHULARIACEAE).

\section{Concentración de hipo clorito de sodio}

\begin{tabular}{lllll}
\hline \multicolumn{1}{c}{ Tiempos } & Repetición I & Repetición 2 & Repetición I & Repetición 2 \\
\hline $\mathbf{1 0}$ minutos & hongos & bacterias & prendimiento & prendimiento \\
$\mathbf{1 5}$ minutos & prendimiento & hongos & muerte & prendimiento \\
$\mathbf{2 0}$ minutos & prendimiento & prendimiento & muerte & muerte \\
$\mathbf{2 5}$ minutos & prendimiento & prendimiento & prendimiento & muerte \\
$\mathbf{3 0}$ minutos & prendimiento & muerte & muerte & muerte \\
$\mathbf{3 5}$ minutos & prendimiento & muerte & prendimiento & muerte \\
$\mathbf{4 0}$ minutos & muerte & muerte & muerte & muerte \\
\hline
\end{tabular}




\section{Cerna y Tafur}

Tabla 2. Diseño experimental para observar el nivel de prendimiento de segmentos nodales en distintos medios de cultivo.

\begin{tabular}{|c|c|c|c|c|c|c|}
\hline $\begin{array}{l}\text { Medio de } \\
\text { cultivo }\end{array}$ & Rep I & Rep 2 & Rep 3 & Rep 4 & Rep 5 & Rep 6 \\
\hline MS & $\begin{array}{l}\text { Desarrolla } \\
\text { segmento } \\
\text { nodal } \\
\text { y raíces }\end{array}$ & $\begin{array}{l}\text { Desarrolla } \\
\text { segmento } \\
\text { nodal } \\
\text { y raíces }\end{array}$ & $\begin{array}{l}\text { Desarrolla } \\
\text { segmento } \\
\text { nodal } \\
\text { y raíces }\end{array}$ & $\begin{array}{l}\text { Desarrolla } \\
\text { segmento } \\
\text { noda } \\
\text { y raíces }\end{array}$ & $\begin{array}{l}\text { Desarrolla } \\
\text { segmento } \\
\text { nodal } \\
\text { y raíces }\end{array}$ & $\begin{array}{l}\text { Desarrolla } \\
\text { segmento } \\
\text { nodal } \\
\text { y raíces }\end{array}$ \\
\hline $\begin{array}{l}\text { MS+ } \\
\text { IBA }\end{array}$ & $\begin{array}{l}\text { Callo } \\
\text { con } 2 \text { nudos } \\
\text { pequeños }\end{array}$ & Muerto & Callo & $\begin{array}{l}\text { Callo } \\
\text { Hojas } \\
\text { deformes }\end{array}$ & Callo & Callo \\
\hline $\begin{array}{l}\text { MS+ } \\
\text { ANA }\end{array}$ & $\begin{array}{l}\text { No } \\
\text { desarrolla }\end{array}$ & $\begin{array}{l}\text { No } \\
\text { desarrolla }\end{array}$ & $\begin{array}{l}\text { No } \\
\text { desarrolla }\end{array}$ & $\begin{array}{l}\text { No } \\
\text { desarrolla }\end{array}$ & $\begin{array}{l}\text { No } \\
\text { desarrolla }\end{array}$ & $\begin{array}{l}\text { No } \\
\text { desarrolla }\end{array}$ \\
\hline $\begin{array}{l}\text { MS+ } \\
2,4-D\end{array}$ & $\begin{array}{l}\text { No } \\
\text { desarrolla }\end{array}$ & $\begin{array}{l}\text { No } \\
\text { desarrolla }\end{array}$ & $\begin{array}{l}\text { No } \\
\text { desarrolla }\end{array}$ & $\begin{array}{l}\text { No } \\
\text { desarrolla }\end{array}$ & $\begin{array}{l}\text { No } \\
\text { desarrolla }\end{array}$ & $\begin{array}{l}\text { No } \\
\text { desarrolla }\end{array}$ \\
\hline
\end{tabular}

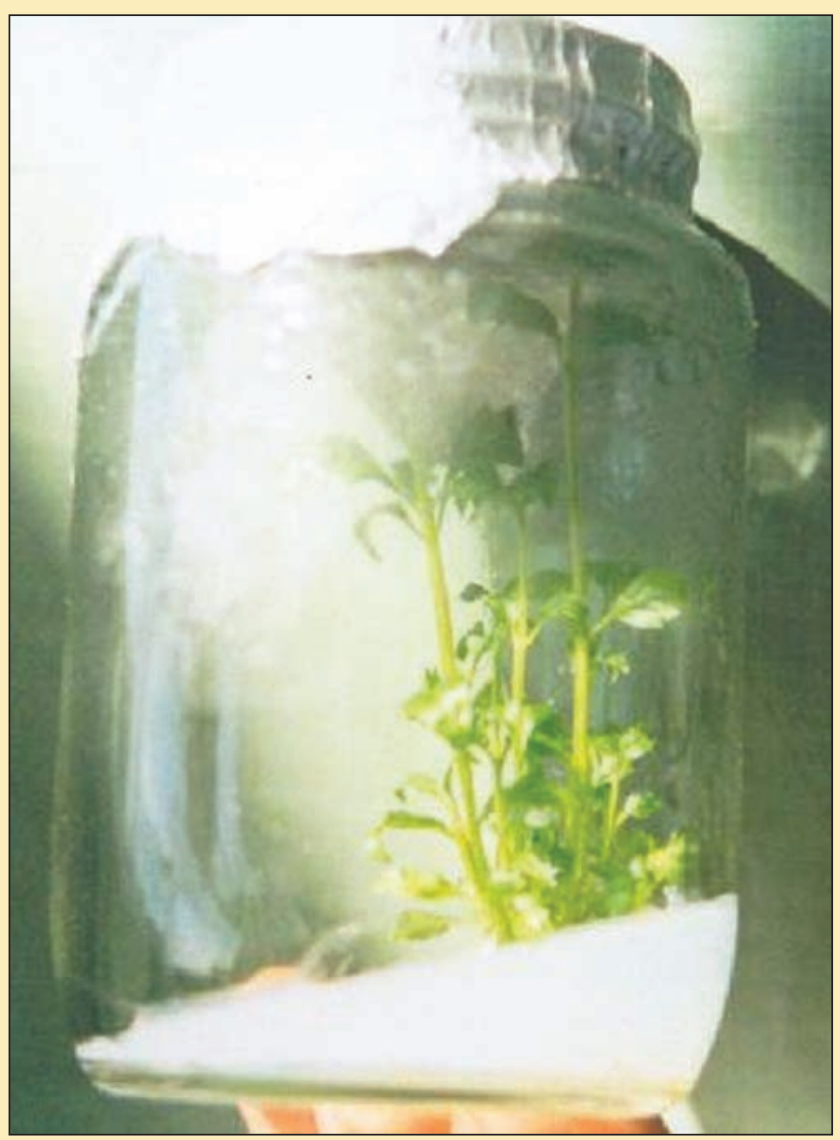

Figura 4. Muestra con desarrollo normal en Cultivo in vitro de Scoparia dulcis L (SCROPHULARIACEAE). Fuente: Marco Cerna.
Se halla que el medio de cultivo más adecuado es el de MS (Murashige \& Skoog) cuya concentración de elementos se detalla (Tabla 2); además se encontró que no es necesario la adición de hormonas. Se muestra también crecimiento y evolución de los segmentos nodales (Figuras 4, 5 y 6).

El tiempo aproximado para obtener plantas maduras de Scoparia dulcis L, utilizando los pasos sugeridos en el protocolo para el cultivo in vitro establecido en esta investigación es de 80 días (Figura 7).

Una vez elegido el medio de cultivo se detallan a continuación los reactivos utilizados en la Tabla 3.

\subsection{Elaboración del medio de cultivo}

Se tomaron alícuotas del Stock, en un recipiente I, II, III, IV, V, las vitamina Mioinositol y se procedió a agregar sacarosa para después aforar con agua al límite (250, 500, I.000 $\mathrm{ml}$ etcétera).

Una vez aforado se añadió Agar-Agar, ajustando el $\mathrm{pH}$ del medio de cultivo a 5,8. Posteriormente, se homogenizó, agitó y elevó la temperatura en microondas durante 3 minutos (con precaución ya que tiende a regarse), y se dosificaron $40 \mathrm{ml}$ del medio de cultivo preparado, mientras estuvo caliente en frascos de $250 \mathrm{ml}$ y se tapó con papel aluminio. 


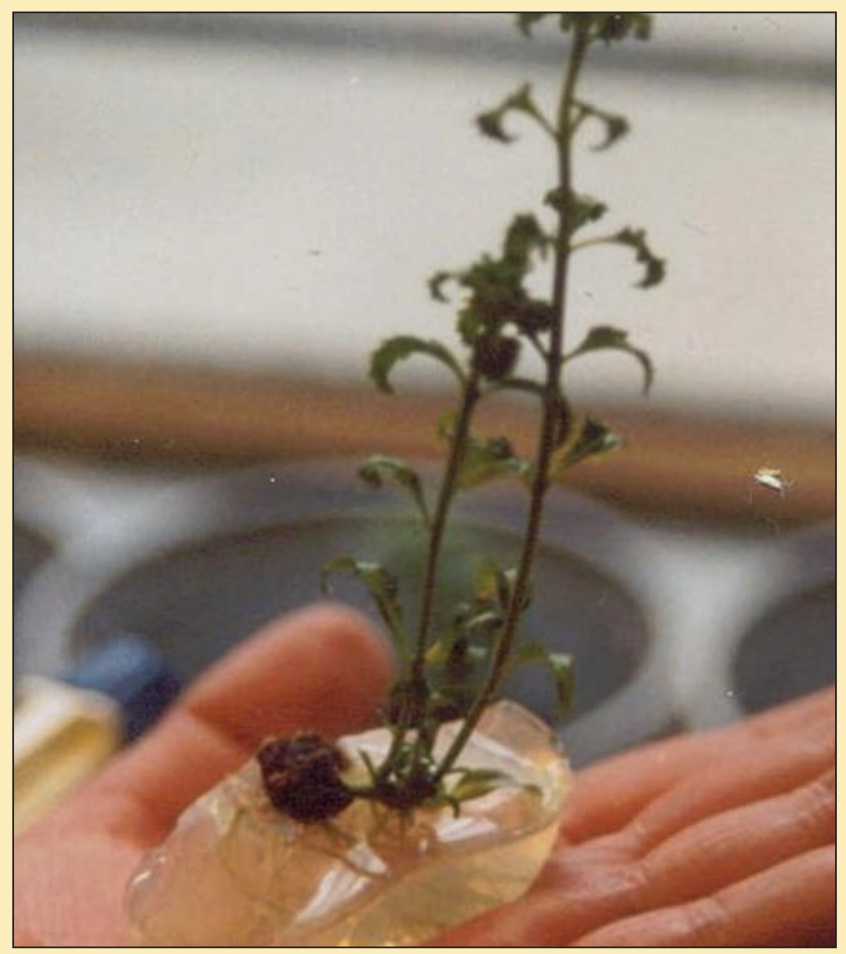

Figura 5. Limpieza de las raíces del medio de cultivo MS. Fuente: Marco Cerna.

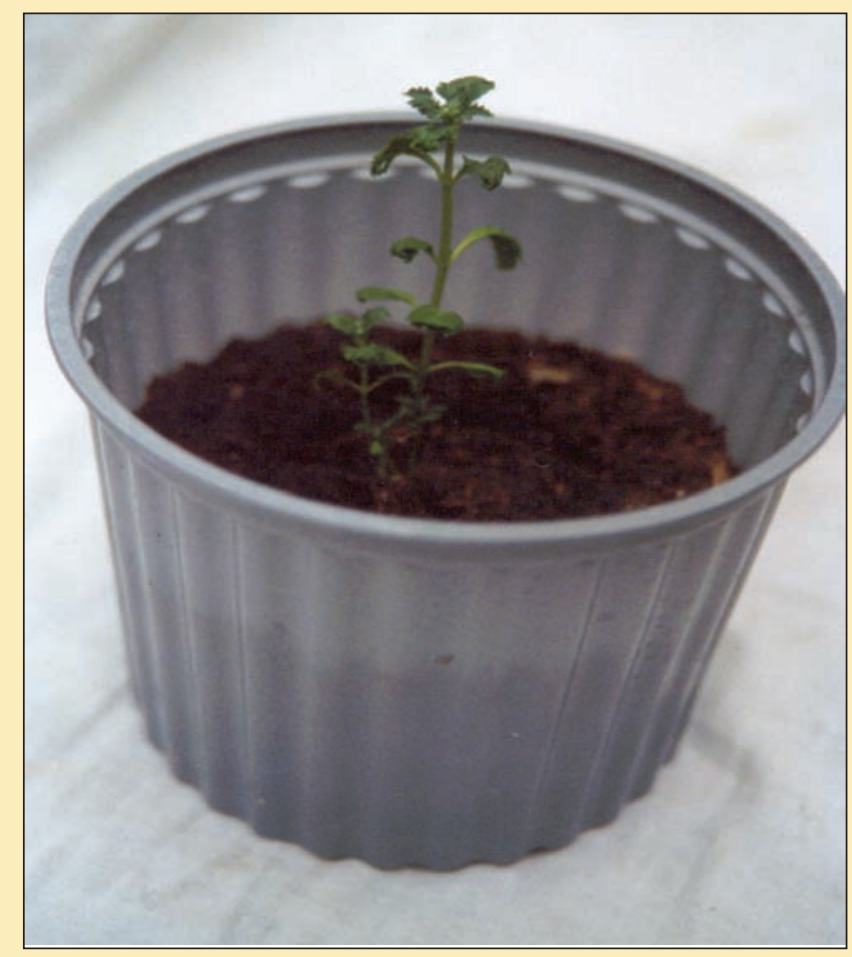

Figura 6. Plantulas de Scoparia dulcis L (SCROPHULARIACEAE) en invernadero, después de 15 días. Fuente: Marco Cerna.

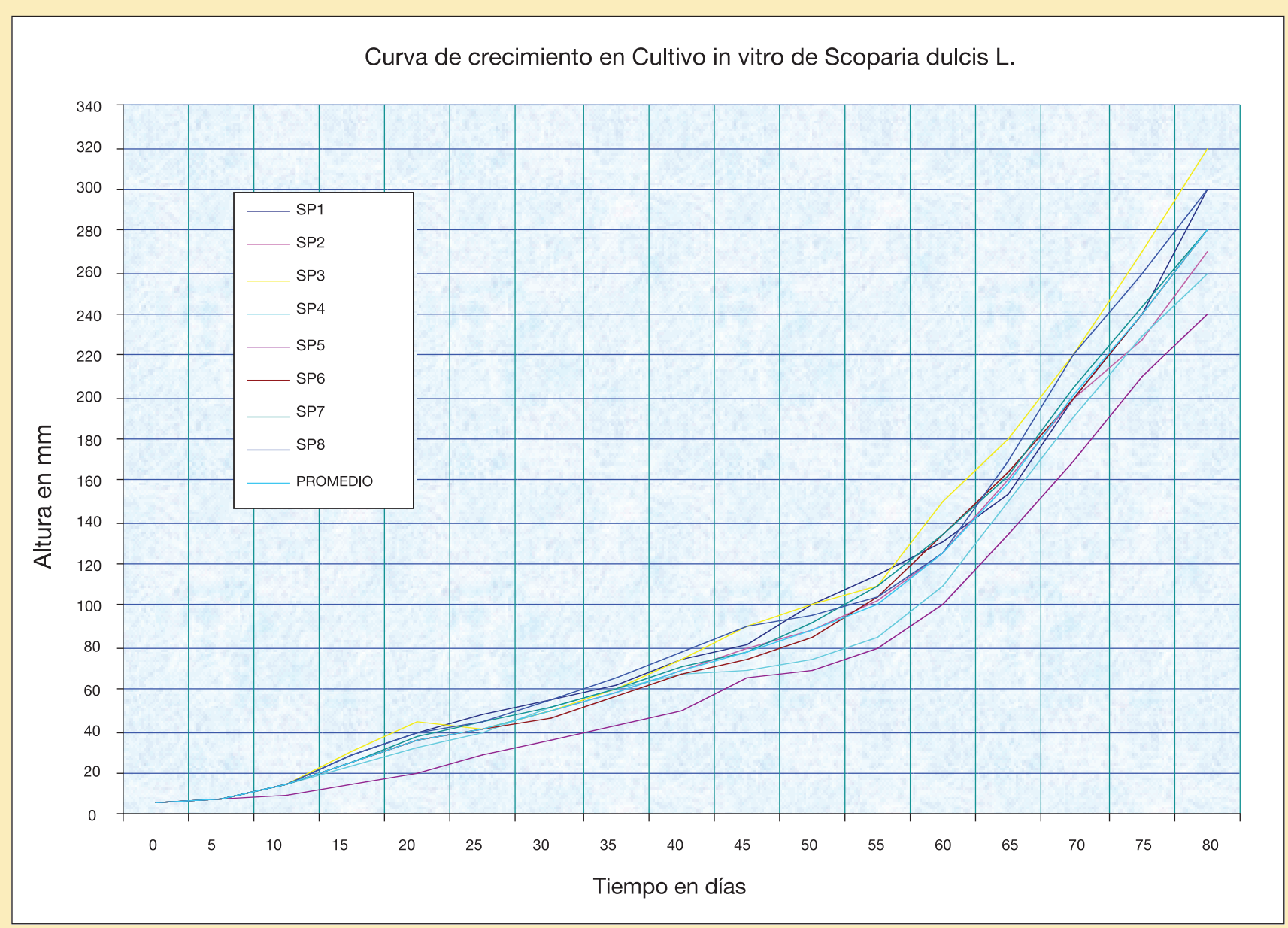

Figura 7. Curva de crecimiento de la Scoparia dulcis L. 
Tabla 3. Reactivos para la elaboración del medio de cultivo de Murashige \& Skoog en Cultivo in vitro de Scoparia dulcis L (SCROPHULARIACEAE)

\begin{tabular}{|c|c|c|c|}
\hline Solución stock & Componentes & $\begin{array}{l}\text { Concentración } \\
\text { gramos / litro }\end{array}$ & $\begin{array}{l}\text { Cantidad para } \\
\text { preparar I litro }\end{array}$ \\
\hline \multirow[b]{2}{*}{ Stock I } & $\mathrm{NH}_{4} \mathrm{NO}_{3}$ & 82,5 & \multirow{2}{*}{$20 \mathrm{ml}$} \\
\hline & $\mathrm{KNO}_{3}$ & 95 & \\
\hline \multirow{4}{*}{ Stock II } & $\mathrm{Mg} \mathrm{SO} 4 \cdot 7 \mathrm{H}_{2} \mathrm{O}$ & 37 & \multirow{4}{*}{$10 \mathrm{ml}$} \\
\hline & $\mathrm{MnSO}_{4} \cdot \mathrm{H}_{2} \mathrm{O}$ & 2,23 & \\
\hline & $\mathrm{Zn} \mathrm{SO} \cdot 7 \mathrm{H}_{2} \mathrm{O}$ & 1,058 & \\
\hline & $\mathrm{Cu} \mathrm{SO} \cdot 5 \cdot 5 \mathrm{H}_{2} \mathrm{O}$ & 0,0025 & \\
\hline \multirow{3}{*}{ Stock III } & $\mathrm{Ca} \mathrm{Cl} 2 \cdot 2 \mathrm{H}_{2} \mathrm{O}$ & 44 & \multirow{3}{*}{$10 \mathrm{ml}$} \\
\hline & KI & 0,083 & \\
\hline & $\mathrm{Co} \mathrm{Cl}_{2} \cdot 6 \mathrm{H}_{2} \mathrm{O}$ & 0,0025 & \\
\hline \multirow{3}{*}{ Stock IV } & $\mathrm{K} \mathrm{H}_{2} \mathrm{PO}_{4}$ & 17 & \multirow{3}{*}{$10 \mathrm{ml}$} \\
\hline & $\mathrm{H}_{3} \mathrm{BO}_{3}$ & 0,62 & \\
\hline & $\mathrm{Na}_{2} \mathrm{MoO}_{4} \cdot 2 \mathrm{H}_{2} \mathrm{O}$ & 0,025 & \\
\hline \multirow{2}{*}{ Stock V } & $\mathrm{Fe} \mathrm{SO} \mathrm{S}_{4} \cdot 7 \mathrm{H}_{2} \mathrm{O}$ & 2,784 & \multirow{2}{*}{$10 \mathrm{ml}$} \\
\hline & $\mathrm{Na}_{2}$ EDTA & 3,724 & \\
\hline \multirow[t]{5}{*}{ Vitaminas } & Ácido nicotínico & 0,05 & $5 \mathrm{ml}$ \\
\hline & Piridoxina & 0,05 & $5 \mathrm{ml}$ \\
\hline & Tiamina & 0,1 & $\mathrm{I} \mathrm{ml}$ \\
\hline & Glicina & 0,2 & $20 \mathrm{ml}$ \\
\hline & Mioinositol & 2,5 & $10 \mathrm{ml}$ \\
\hline
\end{tabular}

\begin{tabular}{lll} 
Fuente de C & Sacarosa & $30 \mathrm{~g}$ \\
\hline Gelatinizador & Aga & $8 \mathrm{~g}$
\end{tabular}

La esterilización de los medios de cultivo se realizó en un autoclave ajustado a 20 libras de presión, durante 20 minutos.

Los frascos conteniendo los explantes se trasladaron a una cámara de incubación que se mantiene a $25 \pm 2{ }^{\circ} \mathrm{C}$, y bajo una intensidad luminosa de 2.000 lux (lámparas fluorescentes).

En esta fase las plántulas pasaron 45 días.

\subsection{Cultivo en invernadero}

Las plántulas obtenidas fueron sometidas al proceso de adaptación al medio ambiente, en un sustrato artificial de cultivo (Cascarilla de arroz piedra pómez y humus) para que se desarrollen bajo condiciones de invernadero.
En esta fase las plántulas pasaron 35 días.

Todo el proceso desde la siembra de los esquejes, hasta la floración de la planta en invernadero tardó aproximadamente 80 días.

\section{Conclusiones}

Con el fin de establecer un rendimiento adecuado de principios activos obtenidos de plantas de origen in vitro es necesario realizar un análisis químico con los extractos de Scoparia dulcis L, para comprobar la existencia de estos principios activos se deberá comparar con los resultados de los análisis hechos en plantas producidas íntegramente en el campo. 
Esta experiencia se desarrolló a nivel piloto, y presenta resultados satisfactorios; siendo conveniente planificar y llevar adelante una fase de experimentación a un nivel mayor.

Habiéndose determinado un protocolo para el cultivo in vitro de Scoparia dulcis $L$, se recomienda continuar los experimentos destinados a la bio-acumulación de principios activos específicos.

\section{Referencias}

Jiemei, Xu y Ji Chaozhen. 1976. Flora of China Illustrations. Vol 18, fig, 35, I-4. Missouri Botanical Garden,
Tropicos Nomenclatural Data Base. En línea: $<$ http://www.mobot.org/>

Pierik, R. 1987. El Cultivo in vitro De Las Plantas Superiores. Departament of Horticulture, Agricultural University. Wageningen, Holanda.

Roca, W y L. Mroginski. I99I (ed). Cultivo de Tejidos en la Agricultura. Publicación CIAT No I5I. Cali.

Taylor, Leslie. 2005. The Healing Power of Rainforest Herbs. En línea: <http://rain-tree.com/book2.htm> TROPICOS, 2002. Nomenclatural Data Base. Missouri Botanical Garden. En línea: <www.mobot.org> 